Nascimento, André Ricardo.

Alumno del programa de doctorado Arte: producción y investigación - Faculdad Bellas Artes San Carlos - becario CAPES Fundacion.

Travisani Giovannone, Tatiana.

Pós-doctoranda de Artes Visuales en la ECA/USP.

\title{
Prácticas del Audiovisual en Tiempo Real: del medio físico al medio telemático.
}

TIPO DE TRABAJO

Comunicación.

PALABRAS CLAVE

Live cinema; audiovisual en tiempo real; performance audiovisual; sistema telamático.

KEY WORDS

Live cinema; audiovisual performance; telematic system.

\section{RESUMEN}

Las performances sonoro-visuales en tiempo real, también llamadas de live cinema, están caracterizadas, primordialmente, por una construcción narrativa no lineal, en que el artista compone la obra durante su propio acontecimiento. Es un hecho donde, tanto los datos cuanto la actuación son determinantes para el resultado final, ocurriendo una simbiosis hombre-máquina en que la imprevisibilidad y el azar permiten novedosas correlaciones.

Para la presente ponencia, discutiremos el proceso narrativo no lineal en la práctica del audiovisual en tiempo real, posibilitando la comprensión de este sistema (audiovisual) como un conjunto de componentes en estado de interacción. Presentaremos también el sistema como un aglomerado de partes independientes, discutiendo su formación a partir de la compresión del concepto de códigos, medios y ritmos en la práctica del live cinema.

Finalmente, hablaremos de la gestión en los medios telemáticos para generar e intercambiar informaciones en tiempo real. En este momento, presentaremos el funcionamiento de una normativa propia de codificación de los componentes que definen la obra, partiendo del medio físico para el medio telemático, retornando al medio físico a través del resultado de la performance en un proceso de transducción y transcodificación audiovisual.

Para explanar las informaciones, presentaremos como estudio de caso el Dúo de live electronic Clássicos de Calçada, proyecto experimental sonoro-visual en tiempo real, basado en experiencias personales y exploración urbana, formado pelos autores de esta preposición: DeCo Nascimento y Tatiana Travisani.

\section{ABSTRACT}

The visual sound real time live performances, also calls live cinema, are characterized, primarily, by a nonlinear narrative construction, in which the artist composed the work during its own event. It is a fact which data and performance are both crucial for the final result, occurring during the human-machine symbiosis where the unpredictability and randomness allow a newfangled correlation.

For this paper, we discuss the nonlinear narrative process in the real time audiovisual practices, enabling the understanding of this system as a set of components on an interaction state. Also we present the system as a cluster of 
independent parties, discussing their training from concept compression codes, media and rhythms in the practice of live cinema.

Finally, we will discuss the arrangement in the electronic media to generate and exchange the real time information. At this point in time, we will present the performance of their own regulations components encoding that define this kind of work, based on the physical environment to telematics, until returning to the physical environment through the result of a performance, that we call as transduction and transcoding audiovisual process.

For grading information, we'll put forward, as a case study, the live electronic duo Clássicos Calçada, a real time audiovisual experimental project, based on personal experiences in urban exploration, formed by the authors of this preposition: DeCo Nascimento and Tatiana Travisani.

\section{CONTENIDO}

\section{PERFORMANCE AUDIVISUAL EN TIEMPO REAL}

Las performances sonoro-visuales en tiempo se caracterizan, primordialmente, por la construcción narrativa no-lineal, donde el artista compone la obra durante su propio acontecimiento, ejecutando simultáneamente imágenes, sonidos y datos en general. Son presentaciones en que la improvisación y el acaso participan del proceso creativo, permitiendo al público experimentar la manifestación de una pieza de autor única e inmersiva.

El resultado estético ocurre durante la acción de los performances, así, tanto los datos cuanto la actuación son determinantes para la repuesta final de la obra, permitiendo que ocurra una simbiosis hombre-máquina donde el inesperado y el azar esencialmente son incorporados de manera dialógica.

Christine Mello (2008), puntúa las transformaciones en los procedimientos creativos en el campo del vídeo, reconociendo una nueva perspectiva a partir del momento en que pasa a ser manipulado y presentado en tiempo real. En estos momentos, él gana un discurso estético libre da dependencia del objeto, rompiendo con el acto contemplativo, incorporando la perdida del objeto y la ausencia, característicos de la performance.

El tiempo simultáneo integrando el procesamiento de datos y la realización de la performance, opera el propio resultado que siempre es independiente y exclusivo, vinculándose solamente con el tiempo presente. Así, el discurso poético gana elementos al alrededor de la modalidad en sí, de las acciones presentadas en un ambiente inmersivo sujeto al imprevisto "de la realidad de un espacio-tiempo construido en el plan del objeto artístico, pasando para la realidad de las manifestaciones procesadas simultáneamente al tiempo en que la creación artística si manifiesta" ${ }^{1,}$.

Las prácticas performáticas sonoro-visuales en tiempo real pueden utilizar posibilidades variadas de métodos, técnicas y conceptos, pero lo que mantiene su unidad es la manera como está desarrollada, integrando el sonido y la imagen durante su propia ejecución en presentaciones públicas.

\section{EL PROYECTO CLÁSSICOS DE CALÇADA}

Clássicos de Calçada, en actividad desde 2013, es un proyecto experimental del artista sonoro DeCo Nascimento y de la vídeo artista Tatiana Travisani. El proyecto consiste en una performance sonoro-visual en tiempo real, basada en experiencias personales de exploración urbana. Son realizadas capturas visuales que buscan reconocer el espacio público a través de la exploración pautada por la poética del error, fundamentada en las deambulaciones surrealistas.

La herramienta utilizada por el dúo fue desarrollada en el entorno de programación Pure Data que está en proceso continuo de modificación y ampliación desde el inicio del proyecto. La performance ofrece el encuentro entre el espacio público y el privado, indicando la dinámica y el ritmo de la calle a partir de las experiencias de los artistas en el paseo. Las estructuras ofrecidas por Clássicos de Calçada apuntan para una estética de manipulaciones electrónicas y analógicas en tiempo real.

Com parte del eje narrativo, utilizamos también la mezcla y el procesamiento de los datos: por un lado la composición, utilizando síntesis sonora con métodos aditivo y substrativo, además de construcción de beats basados en la cultura glitch, deep house y electro

\footnotetext{
${ }^{1}$ MELLO, Christine. Extremidades do vídeo. Editora Senac, São Paulo, 2008, p. 43. [traducción propia]
} 
dub. Por otro lado, complementando la acción visual, utilizamos el live paint y objetos luminoso "callejeros" adquiridos en las deambulaciones.

El patch desarrollado para el proyecto posee parámetros de modificación de imagen, con dos salidas externas: una de imagens prégrabadas y almacenadas en un banco de datos, y otra capturada, en tiempo real, con auxilio de una webcam instalada, posibilitando la mezcla entre ambas. El control de los dados en el ordenador, funciona según el protocolo MIDI, programada para que los efecto

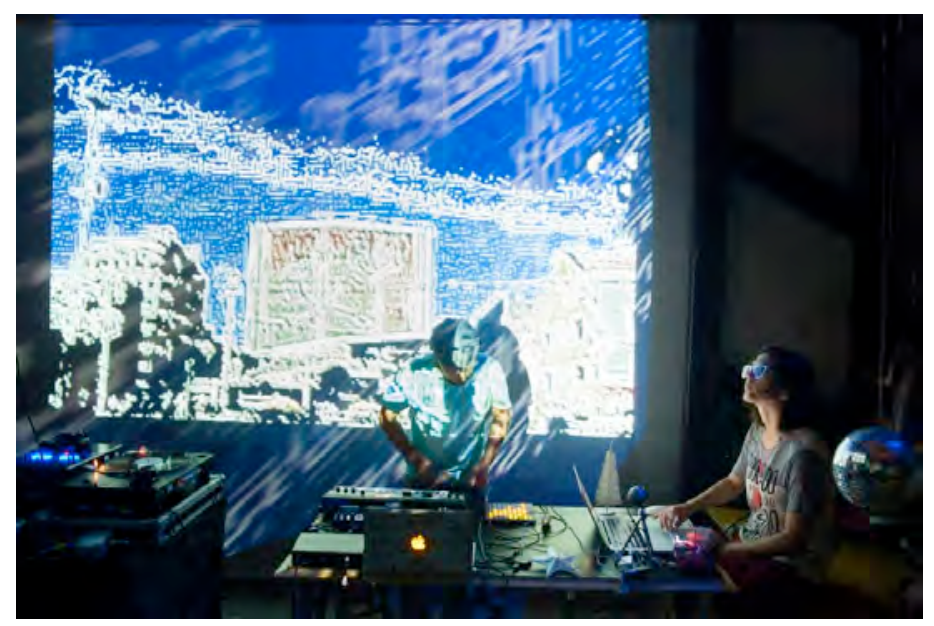

Ilustración 1: Presentación en la Mostra AVAV, São Paulo, dic. 2014

Mia Makela ${ }^{2}$, una de las precursoras en el lenguaje del live cinema, divide los elementos de esta acción performática en cinco etapas: espacio, tiempo, proyección, performance y público. Esas divisiones nos ayudan a reconocer y reflexionar a respecto del proceso creativo de las piezas elaboradas.

En el espacio, encontramos: el espacio físico donde ocurre la acción, el espacio digital donde se procesa el contenido, el espacio del desktop donde se operan los softwares de manipulación y el espacio de la pantalla y de los altavoces donde se la reproduce.

En la etapa del tiempo, están integradas las acciones de la improvisación, de la practica del tiempo real y del bucler, como elemento de la composición sonora-visual. En la etapa de la proyección reparte en: espacio de la proyección (que puede ser una pantalla, un edificio, un tejido con texturas, etc) y en la estructura de los medios (el proyector, luces, instrumentos musicales y altavoces). Finalmente, en performance se aproxima de la posición del performer en las presentaciones audiovisuales, donde no se puede reconocer su ejecución de modo que se mantiene (generalmente) por detrás de su laptop; y del público que tiene un papel distinto del cinema o de una instalación, estando en el medio donde no puede esperar una obra de narrativo lineal y tampoco actuar con su propio cuerpo como a una instalación.

En Clássicos de Calçada todas esas etapas hacen parte de la estructura de la obra y se modifican según cada presentación. Los espacios son siempre distintos uno de los otros, exigiendo una constante adaptación, de este modo el público también cambia, si presentamos en una galería o en una fiesta la respuesta del público es muy distinta una de la otra.

\footnotetext{
${ }^{2}$ MAKELA, Mia. The pratice of live cinema. 2008. (Disponible en el enlace: http://miamakela.net/TEXT/text_PracticeOfLiveCinema.pdf )
} 

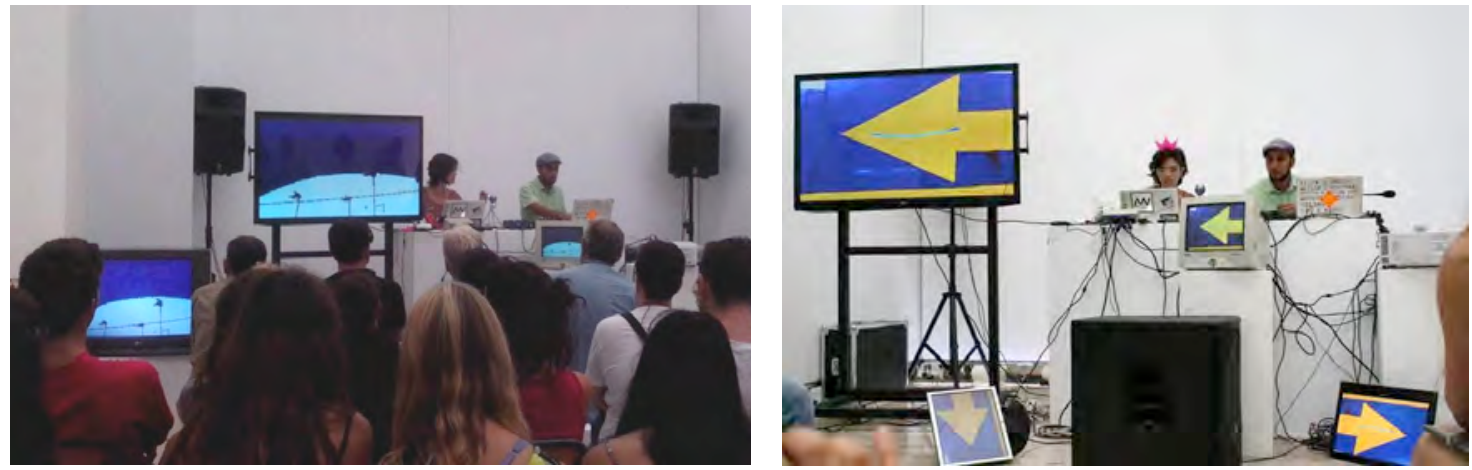

Ilustraciones 2, 3: Presentación multi-pantalla, apertura Master AVM, UPV, Valencia, sep. 2014.

Mismo las etapas enlazadas con la ejecución, como la del tiempo y de la proyección, ni siempre se repiten, el proyecto esta a todo momento integrando nuevos elementos, según la propia experiencia que va adquiriendo con sus presentaciones. Lo que se opera mientras la performance es desarrollada en el espacio físico entre los artistas y sus herramientas telemáticas, es exhibido al público en el mismo momento, posibilitando el surgimiento del error y del descontrol.

\section{EL SISTEMA DESARROLLADO}

En Clássicos de Calçada comprendemos el sistema de audiovisual en tiempo real como un "conjuntos de componentes en estado de interacción" ${ }^{3}$. De esta manera, la interacción o relación entre componentes es una cuestión esencial al sistema. Como nos afirma Vasconcellos:

Es un aspecto central que identifica la existencia del sistema como entidad, distinguido de un simple aglomerado de partes independientes una de las otras (...) para comprender los comportamientos de las partes, tórnase indispensable llevar en consideración las relaciones (...) las relaciones son lo que da cohesión al todo el sistema, otorgándole un carácter de totalidad, una de las características responsables por definir el sistema ${ }^{4}$.

A partir de nuestra investigación sobre la práctica del tiempo real, consideramos como parte fundamental en el proceso de concepción de la obra el concepto de códigos, medios y ritmo. Basados en la cantidad de informaciones producidas y procesadas durante la acción: captura de vídeo, producción sonora a través de sintetizadores y manipulación de las imágenes a través del pach de Pure Data y/o con el auxilio del software Modul 8, sentimos la necesidad de establecer una serie de normas para romper con el caos de las informaciones.

En este sentido compartimos con la idea propuesta por Deleuze y Guatarri acerca del caos, abordada por Obici en su texto sobre el territorio sonoro en los media: "el caos está compuesto por infinitos componentes en curso que, actuando en una velocidad inconmensurable, amenazan el agotamiento de los medios ${ }^{5 \prime \prime}$. De esta manera, teniendo en cuenta la gran cantidad de informaciones en tiempo real fue creado una normativa de codificación de los componentes que definen la obra, partiendo del medio físico para el medio telemático, retomando al medio físico a través de la performance. Este ciclo sería la constitución de la propia obra, en un proceso de transducción y transcodificación, como apunta Obici:

Los códigos si repiten, pero nunca de la misma manera, cada vez que vuelven ellos si transforman por procesos de transducción y transcodificación, tornándose punto de conexión entre medios. En otros términos, todo medio se constituye a partir de una red de códigos en constante cambio ${ }^{6}$.

Aunque el resultado estético de la performance sea la mezcla de las imágenes y de los sonidos, caracterizando la propuesta poética; la estructura de Clássicos de Calçada está basada en los dados manipulados en tiempo real. El acto performático,

\footnotetext{
${ }^{3}$ BERTALANFFY apun VASCONCELOS, Maria José Esteves. O Pensamento Sistêmico: o novo paradigma da ciência. Campinas, Ed. Papirus, 2002 [traducción propia]

${ }^{4}$ VASCONCELOS, Maria José Esteves. O Pensamento Sistêmico: o novo paradigma da ciência. Campinas, Ed. Papirus, 2002, p. 199 [traducción propia]

${ }^{5} \mathrm{OBICI}$, Giuliano Lamberti. Condição da escuta: mídia e território sonoro. Rio de Janeiro, Ed. Viveiro de Castro, 2008, 64 [traducción propia]
} 
funciona como resultado del encuentro entre el ritmo del transito de dados del sistema, con la propuesta poética en abordar elementos visuales y sonoros.

La dinámica que pasa en el flujo de los códigos comprende el ritmo estético de la obra, exigiendo un estado de percepción atento y apto a las pequeñas transformaciones sensibles. De esta forma, el sistema es bien sucedido en la concepción, manejo y recepción.
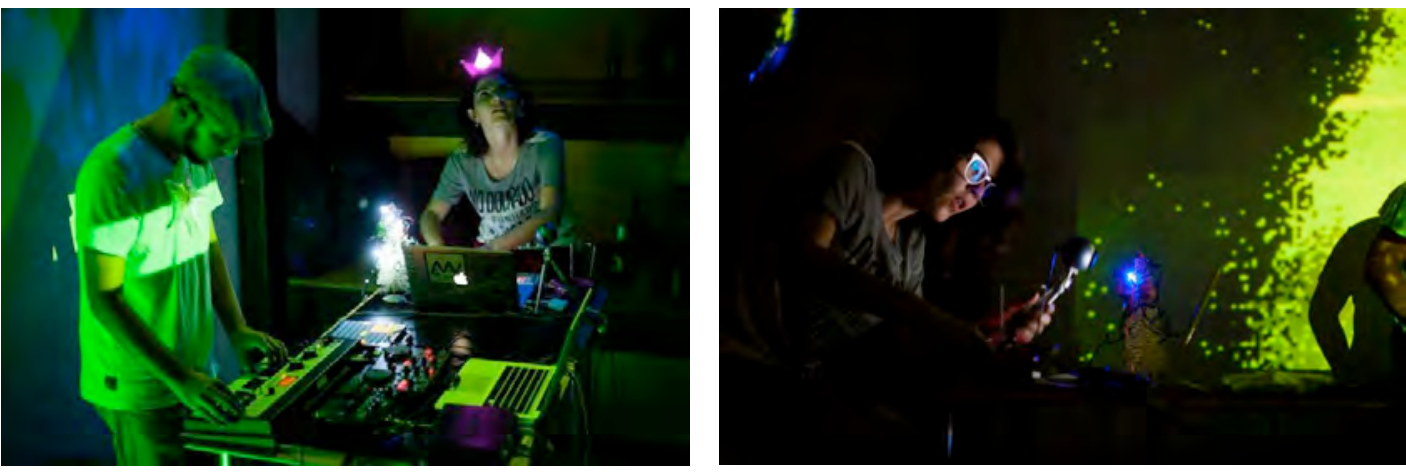

Ilustraciones 4, 5: Presentación en la Mostra AVAV, São Paulo, dic. 2014
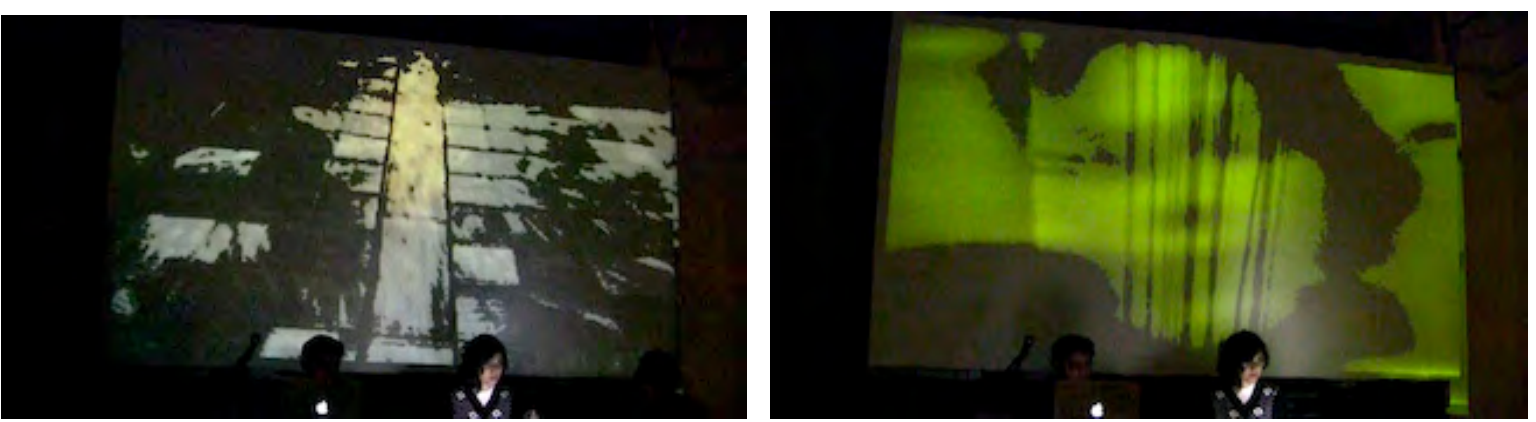

Ilustraciones 6, 7: Presentación en la apertura de la Bienal The Wrong, Plutón, Valencia, dic. 2013

Para la estructuración poética utilizamos el ritmo como fuente de integración de los sistemas. El concepto de ritmo que adoptamos no posee ningún tipo de relación con la estructura temporal utilizada en la música o en el montaje del cine, sino con la finalidad de ordenar el caos del flujo de información generado.

El ritmo es una manera de lidiar con el caos, consiste en aquello que si establece en dos medios. En perspectiva de entradas y salidas, transcodificaciones y transducciones de los códigos, entre un medio y otro medio, acontece lo que se define como ritmo. Algo que esta entre, que no es, que transita, que pasa en este ínterin ${ }^{7}$.

Así, en nuestros trabajos de audiovisual en tiempo real, separamos la cuestión del ritmo en dos momentos: relacionando la dinámica creada entre transito de dados para cada evento del sistema, y con relación al resultado estético generado durante cada actuación.

\footnotetext{
${ }^{7}$ Ibíd.
} 

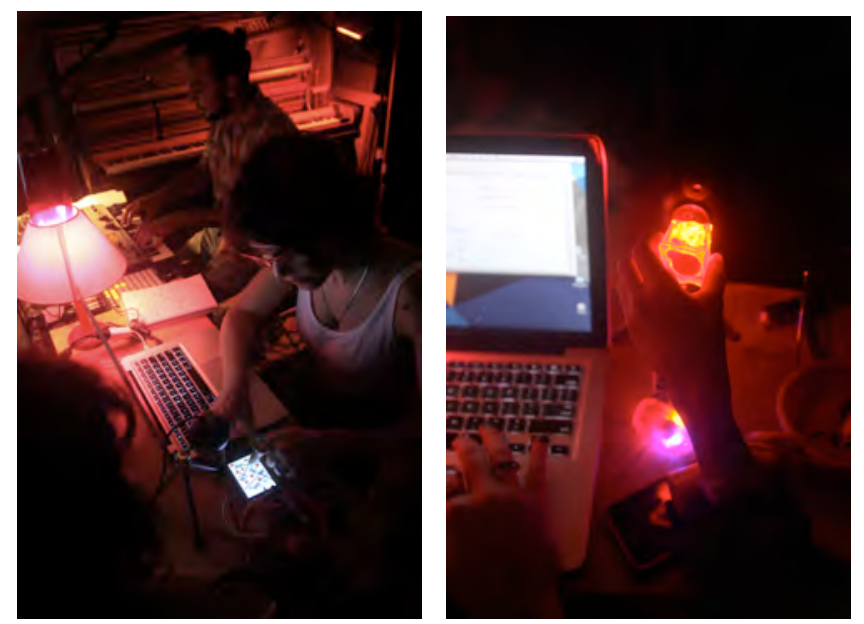

Ilustraciones 8, 9: Presentación en la residencia del Estúdio Fitacrepe, São Paulo, abr. 2015

Dado la experiencia de Clássicos de Calçada en festivales de live cinema, live electronic y muestras de arte sonoro y exploración audio visual, seguimos la propuesta presentada por el artista e investigador del United Vjs, Vj Espeto, cuando dice que hay dos entidades mezclándose en el mismo espacio: el arte y la fiesta. En el proceso de producción estas dos entidades precisan ser respetadas.

Para que esto ocurra, desarrollamos dos patchs en el software livre Pure Data, con la función de descodificar (reconocer códigos), transcodificar (transitar códigos en medios distintos) y descodificar (transformar el código, hacer el ritmo), conforme la separación conceptual sugerida por Deleuze y Guatarri. Además, utilizamos los sonidos como productores de medios.

Estos medios producidos por toda la parafernalia sónica que disponemos para manipular el sonido en tiempo real, asume la responsabilidad de construir los territorios sonoros durante la acción. La sonificación del territorio crea un estadio de afecto y es justo este espacio creado que va proporcionar el encuentro entre la acción y las entidades mencionadas anteriormente.

\section{CONSIDERACIONES FINALES}

Podemos decir que las practicas audiovisuales en tiempo real poseen estructuras creativas que pasan por distintos procesos de desarrollo, desde su concepción conceptual hasta la presentación pública. Lo que percibimos y sentimos, en nuestro proceso creativo, es una dialogo intenso en las relaciones entre la captura y producción en medios físicos, dirigido a los medios telemáticas. Mientras que la comunicación hombre-máquina simboliza esta relación, en un juego continuo donde la improvisación y la sinergía del ambiente sean la dimensión que define los resultados estéticos.

Nos apoyamos en los conceptos poéticos de la obra, en las etapas de la performance y en el sistema desarrollado para tener el máximo de garantías posibles para que la pieza mantenga su integridad estética, pero es justamente los factores más sutiles y intangibles que permiten la exclusividad y la personalidad del acontecimiento de la acción. Si nuestra inspiración esencial es la calle y sus constantes modificaciones, quizás lo más intenso de nuestro trabajo esté justamente en la capacidad de percibir los cambios y las nuevas necesidades adaptando el método permanentemente.

\section{FUENTES REFERENCIALES}

DELEUZE, Giles; GUATARRI, Felix. Mil Platôs: capitalismo e esquizofrenia. Vol I, II, III e IV. Rio de Janeiro, Ed. $34,2005$.

MAKELA, Mia. The pratice of live cinema. (Disponible en el enlace: http://miamakela.net/TEXT/text_PracticeOfLiveCinema.pdf ), 2008.

MELLO, Christine. Extremidades do vídeo. Editora Senac, São Paulo, 2008.

OBICI, Giuliano Lamberti. Condição da escuta: mídia e território sonoro. Rio de Janeiro, Ed. Viveiro de Castro, 2008.

TRAVISANI, Tatiana Giovannone. REDES e CIDADES em REDES. Tese de doutorado, Artes Visuais - ECA/USP, 2013.

VASCONCELOS, Maria José Esteves. O Pensamento Sistêmico: o novo paradigma da ciência. Campinas, Ed. Papirus, 2002. 